\title{
QUESTION ANSWERING SYSTEM INFORMASI PARIWISATA KOTA PALEMBANG
}

\author{
Marga Lenni ${ }^{1}$, R. Kristoforus Jawa Bendi ${ }^{2}$ \\ Mahasiswa Universitas Katolik Musi Charitas ${ }^{1}$, \\ Dosen Universitas Katolik Musi Charitas ${ }^{2}$ \\ Jalan Bangau No. 60, Palembang \\ Sur-el : margalenni@yahoo.com ${ }^{1}$, kristojb@gmail.com²
}

\begin{abstract}
The development of information technology is very rapid, resulting in an overflow of data. The amount of data can be used to obtain information needed by the user. The problem is, not all information can be found easily, especially very specific information. Likewise information about tourism. One way to overcome these problems is to utilize Natural Language Processing Technology, especially Question Answering System, which allows Computers to understand the meaning of Questions posed by users in natural languages. This study built a simple Question Answering System application. Application developed with PHP programming language, and MySql database. Preprocessing techniques used are Tokenization, Part-Of-Speech tagging, and Named Entity Recognation. The test result show that the application is able to provide answers to user questions of $82,05 \%$.
\end{abstract}

Keywords: Tourism, Natural Language Processing, Question Answering System, PHP, MySql

\begin{abstract}
Abstrak : Perkembangan teknologi informasi yang sangat pesat, mengakibatkan luapan data. Banyaknya data tersebut dapat digunakan untuk memperoleh informasi yang dibutuhkan oleh pengguna. Permasalahannya, tidak semua informasi dapat ditemukan dengan mudah terutama informasi yang sangat spesifik. Demikian halnya informasi mengenai pariwisata. Salah satu cara untuk mengatasi permasalahan tersebut adalah dengan memanfaatkan teknologi Natural Language Processing khususnya Question Answering System yang memungkinkan komputer dapat memahami maksud pertanyaan yang diajukan oleh pengguna dalam bahasa alami. Penelitian ini membangun sebuah aplikasi Question Answering System sederhana. Aplikasi dikembangkan dengan bahasa pemograman PHP, dan database MySql. Teknik Preprocessing yang digunakan adalah Tokenization, Part-Of-Speech tagging, dan Named Entity Recognation. Hasil pengujian menunjukan aplikasi mampu memberikan jawaban pertanyaan pengguna sebesar $82,05 \%$.
\end{abstract}

Kata kunci: Pariwisata, Natural Language Processing, Question Answering System, PHP, MySql

\section{PENDAHULUAN}

Kemajuan teknologi dan informasi semakin meningkat dan berkembang sangat pesat. Kehadiran mesin-mesin pencari seperti (search engines) seperti google (www.google.com), yahoo (www.yahoo.com), Altavista (www.altavista.com) dan sebagainya, dapat memberikan kemudahan untuk mencari dan menemukan informasi di Web. [1]. Informasi yang ada di internet dapat diakses dari berbagai macam perangkat seperti komputer, laptop, smartphone, tablet, dan masih banyak lagi perangkat yang dapat digunakan. Sayangnya, tidak semua informasi dapat dicari dengan praktis dan cepat terutama informasi mengenai tempat wisata kota Palembang.

Kota Palembang merupakan ibu kota provinsi Sumatera Selatan. Palembang adalah kota terbesar kedua di Sumatera setelah Kota Medan. Kota Palembang pada abad ke-9 juga disebut sebagai Bumi Sriwijaya. Berdasarkan 
prasasti kedudukan bukit yang ditemukan dibukit Siguntang sebelah barat kota Palembang yang menyatakan pembentukan sebuah wanua yang ditafsirkan sebagai kota pada tanggal 17 Juni 688 Masehi menjadikan kota Palembang sebagai kota tertua di Indonesia. [2]. Wisatawan yang ada dikota Palembang sejak tahun 2009 hingga akhir 2017 terus mengalami peningkatan. Data tersebut sebesar 303,63 persen, dimana tahun 2009 ada 675.698 wisatawan dan pada akhir 2017 tercatat mencapai 2.011.417 wisatawan. Peningkatan secara signifikan ini tentu tidak lepas dari upaya pemerintahan yang terus melakukan segala upaya dalam menambah tempat wisata dikota Palembang. Tercatat hingga saat ini ada 65 total destinasi yang terdiri dari wisata alam, wisata sejarah dan budaya serta wisata hasil buatan manusia.[3].

Berdasarkan survei yang telah dilakukan pada tanggal 12 Oktober 2018 dengan melibatkan 10 responden terhadap masyarakat yang ada dikota Palembang, ditemukan bahwa masih banyak masyarakat dikota Palembang yang belum mengetahui tentang seberapa banyak tempat wisata yang ada dikota Palembang, kemudian ditemukan adanya kendala dalam memperoleh informasi seperti kesulitan mencari informasi yang ada di internet dikarenakan banyaknya iklan dan hal-hal yang tidak diperlukan ikut tampil pada halaman penelusuran. Hal ini mengakibatkan jumlah data yang relatif besar dan membutuhkan waktu tunggu yang cukup lama untuk mengakses halaman tersebut.

Berdasarkan permasalahan diatas, solusi yang bisa ditawarkan berupa Question
Answering System (QAS). Question Answering System merupakan sebuah sistem yang memungkinkan komputer dapat memahami maksud pertanyaan yang diajukan oleh pengguna dengan menggunakan bahasa alami dan merespon pertanyaan tersebut berdasarkan informasi yang ada.[4]. Jadi dengan adanya Question Answering System informasi pariwisata kota Palembang, wisatawan maupun masyarakat umum yang ada dikota Palembang serta masyarakat yang ada diluar kota Palembang dapat dengan mudah untuk mencari dan mendapatkan informasi-informasi mengenai pariwisata yang ada dikota Palembang.

\section{METODOLOGI PENELITIAN}

\subsection{Arsitektur Sistem}

Arsitektur sistem merupakan suatu pemetaan atau rencana kebutuhan-kebutuhan sistem didalam suatu organisasi.[5]. Gambar 1 memperlihatkan arsitektur sistem yang akan dibangun. Aplikasi Question Answering System yang dibangun merupakan aplikasi basis web. Secara umum, pengguna akan mengakses laman web dan memasukkan sebuah kalimat pertanyaan terkait informasi pariwisata kota Palembang. Kalimat pertanyaan tersebut akan melalui tahapan praproses yang meliputi proses Tokenization, Part-Of-Speech Tagging, dan Named Entity Recognition. Hasil praposes tersebut kemudian digunakan untuk memroses jawaban. Pemrosesan jawaban dilakukan dengan memetakan hasil praproses ke dalam sintaks SQL yang bersesuaian. Selanjutnya sintaks SQL tersebut digunakan untuk melakukan query 
informasi pada basis data. Hasil query tersebut merupakan jawaban yang akan diberikan kepada pengguna.

\subsection{Analisis Pertanyaan}

Berikut adalah sampel-sampel pertanyaan mengenai informasi pariwisata kota Palembang yang berhasil dikumpulkan berdasarkan kebutuhan pengguna melalui penyebaran kuisioner dan wawancara lisan terhadap beberapa masyarakat yang ada dikota palembang. Pertanyaan-pertanyaan tersebut didapatkan 3 kata tanya yaitu apa, berapa, dan dimana yang masing-masing pertanyaan telah diurutkan menurut kata tanyanya, kemudian pertanyaan-pertanyaan tersebut yang nantinya akan dilakukan pengujian lagi terhadap beberapa masyarakat yang ada di kota Palembang agar dapat mengetahui berapa persentase sistem dapat menjawab sesuai kebutuhan dari pengguna. Sampel-sampel pertanyaan dapat dilihat pada Tabel 1

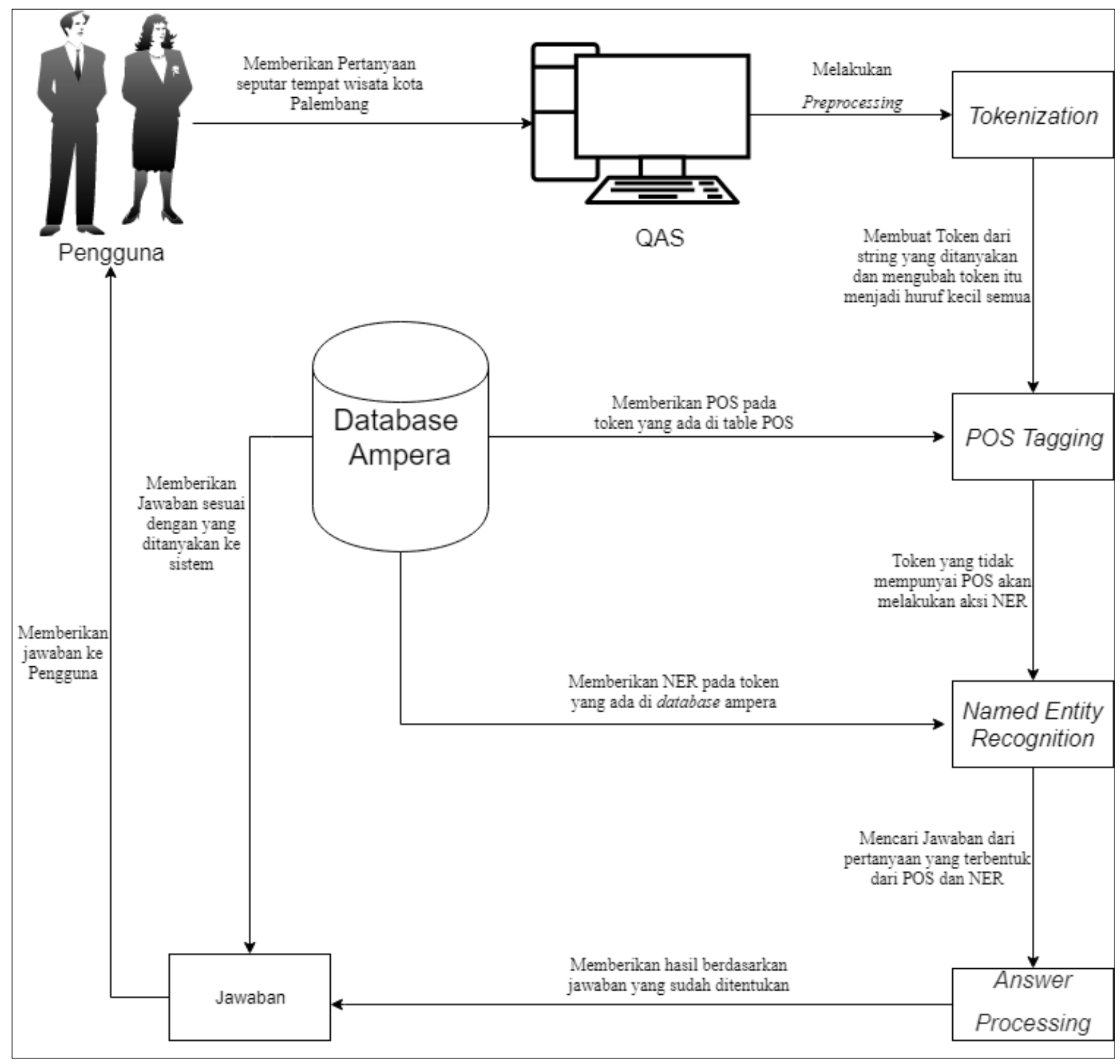

Gambar 1. Arsitektur Sistem QAS 
Tabel 1. Sampel Pertanyaan

\begin{tabular}{cll}
\hline No & \multicolumn{1}{c}{ Keterangan } & Contoh pertanyaan \\
\hline 1 Pertanyaan & - & Apa saja tempat wisata \\
informasi tempat & dikota Palembang \\
wisata dikota & - & Apa tempat wisata dikota \\
Palembang & Palembang \\
dengan kata & - Apa saja tempat wisata \\
tanya "Apa" & yang ada dikota Palembang \\
& - Apa tempat wisata yang \\
& ada dikota Palembang \\
& - Apa tempat wisata di \\
& Palembang \\
& - Apa saja tempat wisata X \\
& dikota Palembang \\
& - Apa saja tempat wisata X \\
& yang ada di kota \\
& Palembang
\end{tabular}

2 Pertanyaan - Berapa tempat wisata yang informasi tempat ada dikota Palembang wisata dikota - Berapa tempat wisata Palembang dikota Palembang dengan kata - Berapa total tempat wisata tanya "Berapa" yang ada dikota Palembang

- Berapa total tempat wisata dikota Palembang

- Berapa banyak tempat wisata yang ada dikota Palembang

- Berapa banyak tempat wisata dikota Palembang

- Berapa tempat wisata X yang ada dikota Palembang

- Berapa tempat wisata X dikota Palembang

- Berapa total tempat wisata $\mathrm{X}$ yang ada dikota Palembang

- Berapa total tempat wisata $\mathrm{X}$ dikota Palembang

- Berapa banyak tempat wisata $\mathrm{X}$ yang ada dikota Palembang

- Berapa banyak tempat wisata X dikota Palembang

3 Pertanyaan - Dimana letak tempat informasi tempat wisata $\mathrm{X}$ wisata dikota - Dimana letak X

Palembang - Dimana lokasi tempat dengan kata wisata $\mathrm{X}$ tanya "Dimana" - Dimana lokasi X

\subsection{Analisis Tokenization}

Tokenization digunakan untuk memotong suatu kalimat yang akan ditanyakan menjadi bagian unit terkecil. Metode yang paling sederhana yang digunakan untuk tokenization adalah memisahkan suatu kalimat berdasarkan spasi. [6]. Selain memisahkan berdasarkan spasi dilakukan juga pengecekan berdasarkan katakata tertentu seperti nama tempat wisata dan lokasi yang nantinya akan ditanya tidak akan di tokenization. Fungsinya supaya pertanyaan yang ditanyakan jawabannya lebih akurat dan sesuai dengan apa yang diharapkan. Sebagai contoh, jika pertanyaan

\section{["Dimana lokasi Benteng Kuto Besak"]}

maka langkah pertama yang akan dilakukan adalah pemisahan string berdasarkan spasi yang hasilnya menjadi

\section{["Dimana"], [“lokasi”], [“Benteng Kuto Besak"]}

Setelah dilakukan proses tokenization maka hasilnya akan diubah menjadi huruf kecil semua yang hasilnya menjadi

["dimana"], ["lokasi"], ["benteng kuto besak"] Pengubahan huruf kecil dilakukan agar dapat mempermudah pencarian data pada database.

\subsection{Analisis POS}

POS (Part Of Speech) adalah kumpulan tata bahasa yang terdiri dari kata kerja, kata benda, kata sifat, dan lain-lain. Proses ini dilakukan setelah tokenization.[7]. Agar sistem dapat memahami dan membaca jenis kataperkata pada suatu kalimat maka diperlukanlah pelabelan POS. [8]. Namun tidak semua jenis POS yang akan diambil, pada Question Answering System informasi pariwisata kota 
Palembang ini akan menggunakan 5 jenis kata yang dianggap perlu atau dibutuhkan pada sistem ini. Berikut daftar POS yang dapat dilihat pada Tabel 2.

Tabel 2. Daftar POS

\begin{tabular}{|c|c|c|}
\hline No & Tag & Kata yang digunakan \\
\hline 1 & WH (Kata Tanya) & $\begin{array}{l}\text { Apa, Berapa, dan, } \\
\text { Dimana }\end{array}$ \\
\hline 2 & $\begin{array}{l}\text { NN (Kata Benda } \\
\text { Umum) }\end{array}$ & $\begin{array}{l}\text { Tempat wisata, } \\
\text { Lokasi, Banyak, } \\
\text { Total, Letak }\end{array}$ \\
\hline 3 & RB (Keterangan) & Saja \\
\hline 4 & SC (Kata Hubung) & Yang \\
\hline 5 & IN (Kata Depan) & Ada \\
\hline
\end{tabular}

Apabila string hasil token tidak ditemukan ditabel POS, maka hasil yang tidak ada tersebut akan ditulis dengan tag POS. Sebagai contoh :

["dimana" = WH], ["lokasi" = NN], ["benteng kuto besak" = POS]

Hasil tersebut didapatkan bahwa benteng kuto besak tidak memiliki POS oleh karena itu ditulis dengan tag POS

\subsection{Analisis Named Entity Recognition}

NER (Named Entity Recognition) adalah pengenalan sejumlah entity seperti person, location, organization, date, money, dan entity lainnya pada teks .[9]. Pada Qestion Answering System informasi pariwisata kota Palembang ini NER digunakan untuk membedakan kata yang merupakan nama objek dan yang bukan objek, pada sistem ini yang menjadi objek itulah yang nantinya akan dicari di database untuk menemukan jawaban yang sesuai dengan pertayaan yang diajukan pengguna. Cara sederhana yang digunakan untuk menentukan NER dilihat dari hasil POS. Jika ada token yang tidak mendapatkan POS maka token tersebut merupakan objek yang akan dicari untuk ditetapkan sebagai NER. Pada Question Answering System informasi pariwisata kota Palembang ini menggunakan 2 NER yaitu NER jenis dari tabel jenis kebudayaan dan NER wisata dari tabel kebudayaan. Untuk kata yang tidak memiliki POS maka kata tersebut akan dicari satu persatu di tabel kebudayaan namun, jika tidak ditemukan ditabel kebudayaan maka akan dilanjutkan pencarian di tabel jenis kebudayan. Jika dari kedua tabel tersebut tidak berhasil ditemukan NER nya, maka sistem menganggap NER tersebut other. Tetapi jika setelah melakukan pencarian dan NER berhasil ditemukan maka kata yang tidak memiliki POS tadi akan diberi entitas. Sebagai contoh :

["dimana" = WH], ["lokasi" = NN], ["benteng kuto besak" = wisata]

Hasil tersebut didapatkan benteng kuto besak sebagai entitasnya dikarenakan benteng kuto besak terdapat ditabel kebudayaan pada database. Oleh karena itu benteng kuto besak merupakan NER wisata.

\subsection{Analisis Validasi Pertanyaan}

Pertanyaan yang dimasukan oleh pengguna akan memalui proses validasi pertanyaan terlebih dahulu sebelum memasuki tahap answer processing. Fungsi dari validasi pertanyaan digunakan untuk mengecek apakah pertanyaan yang diajukan oleh pengguna sudah sesuai atau belum sesuai, jika sesuai maka pertanyaan tersebut akan dijawab namun apabila tidak sesuai maka pertanyaan tersebut tidak dapat dijawab. Validasi pertanyaan dilakukan 
setelah tahap tokenization, POS tagging, dan NER selesai dilakukan. tahap yang dilakukan untuk melakukan validasi pertanyaan yaitu dengan cara mengestrak POS dan NER pada suatu pertanyaan, kemudian dicocokan dengan daftar urutan POS dan NER yang sudah disiapkan.

Daftar urutan POS dan NER akan disimpan di database pada tabel whitepos kemudian sistem akan mengecek apakah pertanyaan yang diajukan oleh pengguna urutan POS dan NER sesuai dengan yang di tabel whitepos. Daftar urutan POS dan NER yang sudah disiapkan dapat dilihat pada Tabel 3.

Tabel 3. Daftar Urutan POS dan NER

\begin{tabular}{ll}
\hline No & \multicolumn{1}{c}{ Aturan } \\
\hline $\mathbf{1}$ & WH RB NN NN other NNP wisata \\
$\mathbf{2}$ & WH NN NN other NNP \\
$\mathbf{3}$ & WH NN NN SC IN other NNP wisata \\
$\mathbf{4}$ & WH RB NN NN other other NNP wisata \\
$\mathbf{5}$ & WH RB NN NN jenis other NNP wisata \\
$\mathbf{6}$ & WH RB NN NN jenis SC IN other NNP wisata \\
$\mathbf{7}$ & WH NN NN SC IN other NNP wisata \\
$\mathbf{8}$ & WH NN NN other NNP wisata \\
$\mathbf{9}$ & WH NN NN NN SC IN other NNP wisata \\
$\mathbf{1 0}$ & WH NN NN NN other NNP wisata \\
$\mathbf{1 1}$ & WH NN NN jenis SC IN other NNP wisata \\
$\mathbf{1 2}$ & WH NN NN jenis other NNP wisata \\
$\mathbf{1 3}$ & WH NN NN NN jenis SC IN other NNP wisata \\
$\mathbf{1 4}$ & WH NN NN NN jenis other NNP wisata \\
$\mathbf{1 5}$ & WH NN NN NN wisata \\
$\mathbf{1 6}$ & WH NN wisata \\
\hline
\end{tabular}

\subsection{Analisis Answer Processing}

Answer processing merupakan tahapan proses dimana pertanyaan yang ditanyakan akan dijawab oleh sistem. Tahapan answer processing dilakukan setelah teknik preprocessing selesai dilakukan. Jadi setelah pertanyaan yang diajukan user melewati tahapan tokenization, POS, dan NER, kemudian pertanyaan tersebut didapatkan valid atau sesuai dengan POS yang sudah disiapkan maka langkah selanjutnya adalah pengecekan kata tanya yang akan digunakan, ada 3 kata tanya yang bisa dipakai pada sistem ini yaitu apa, berapa, dan dimana. Misalnya pertanyaan "dimana lokasi benteng kuto besak", kata tanya yang digunakan adalah "dimana". Setelah mengetahui kata tanya yang digunakan, langkah selanjutnya adalah mencocokan pola kalimat yang digunakan dengan kata kunci yang ada pada kalimat tanya seperti wisata, tipe, dan tempat. Fungsi kata kunci digunakan untuk mempermudah program agar dapat memahami maksud dari pertanyaan yang diajukan oleh $u s e r$. Berikut flowchart dari proses answer processing yang dapat dilihat pada Gambar 2.

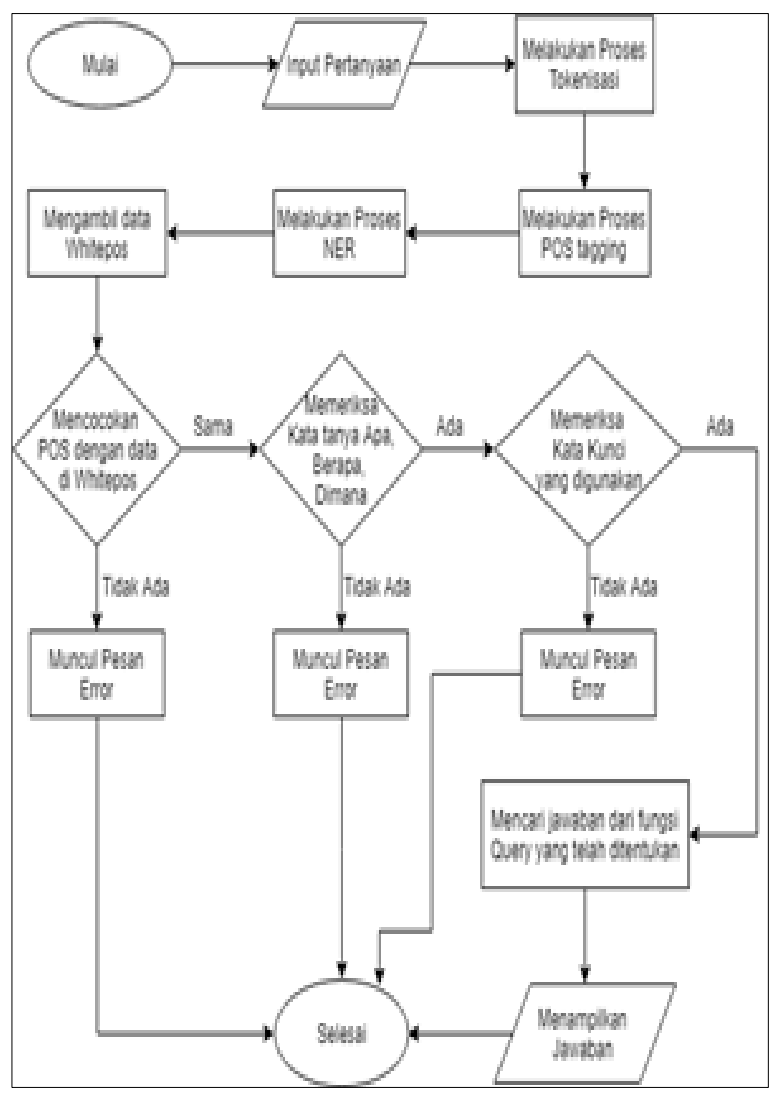

Gambar 2. Flowchart Answer Processing 


\subsection{Implementasi Tampilan Interface}

\subsubsection{Interface Halaman Utama}

Halaman utama ini digunakan untuk pengguna yang ingin melakukan pertanyaan kepada Question Answering System informasi pariwisata kota Palembang, pengguna juga bisa membuka halaman bantuan atau halaman tentang kami. Berikut adalah tampilan interface dari halaman utama dapat dilihat pada Gambar 3

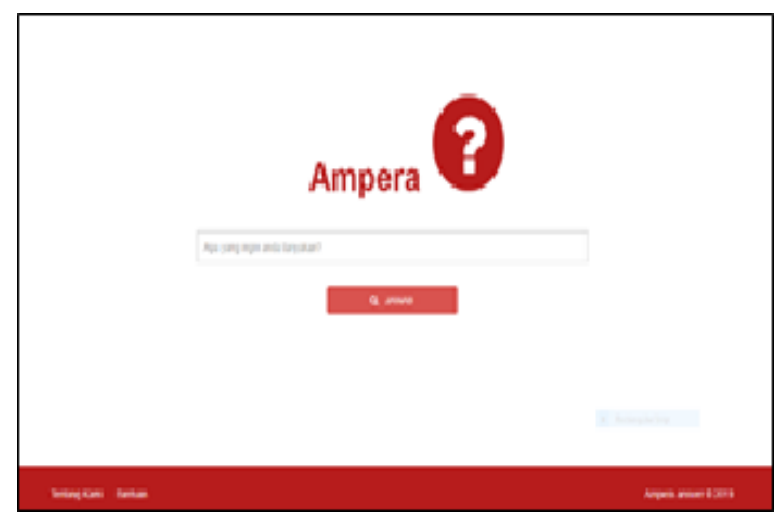

Gambar 3. Interface Halaman Utama

\subsubsection{Interface Halaman Jawaban}

Pada saat pengguna bertanya kepada sistem, maka sistem akan secara otomatis mengarah ke halaman jawaban. Halaman jawaban akan menampilkan hasil jawaban dari pertanyaan yang diajukan oleh pengguna. Berikut adalah tampilan Interface halaman jawaban yang dapat dilihat pada Gambar 4.

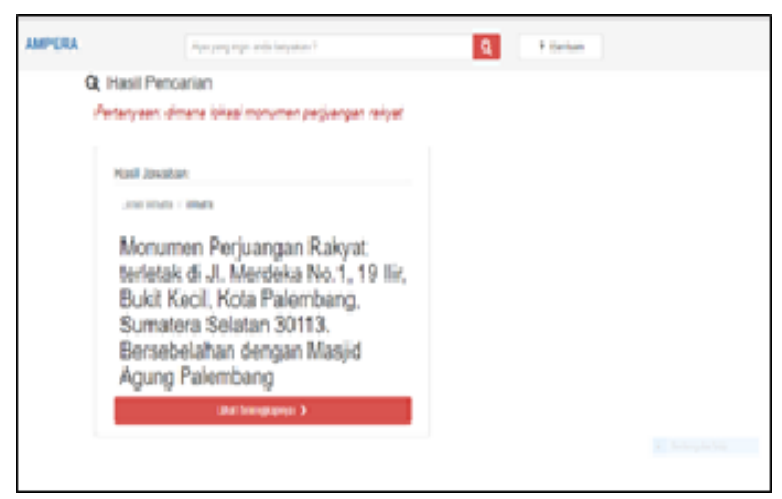

\subsubsection{Interface Halaman Selengkapnya}

Halaman lihat selengkapnya hanya akan terbuka jika pengguna menekan tombol lihat selengkapnya yang terdapat pada halaman jawaban. Tampilan halaman lihat selengkapnya dapat berupa informasi keterangan singkat dari tempat wisata, jam operasional serta biaya masuk jika diperlukan. Berikut adalah tampilan interface dari halaman lihat selengkapnya dapat dilihat pada Gambar 5.

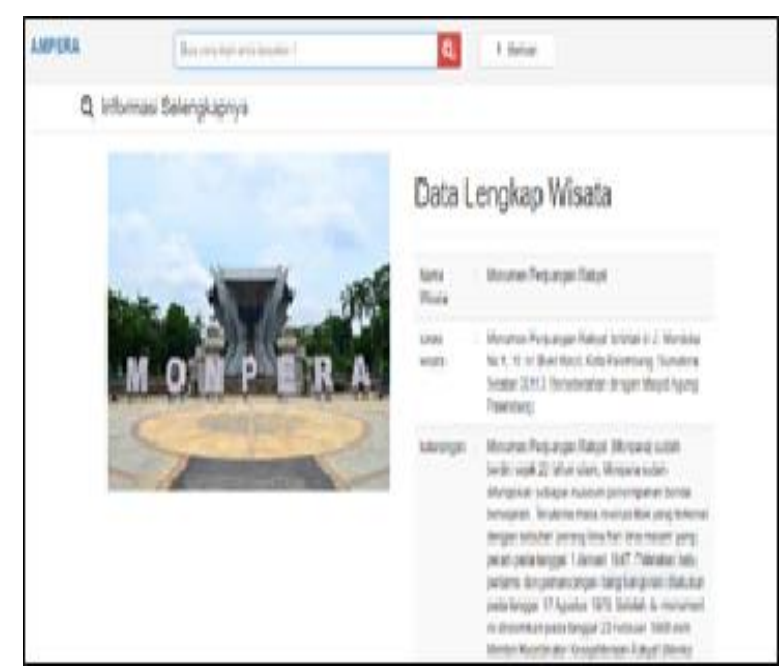

\section{Gambar 5. Interface Halaman Lihat Selengkapnya}

\subsubsection{Interface Jawaban Tidak Ditemukan}

Halaman jawaban tidak ditemukan digunakan untuk menampilkan informasi jawaban yang tidak dapat ditemukan oleh sistem kepada pengguna. Jika pengguna salah memasukan pertanyaan, seperti pertanyaan tersebut tidak terdapat kata tanya atau pola pertanyaannya tidak sesuai maka pesan pemberitahuan tersebut akan muncul untuk memberitahu kepada pengguna jika ada kesalahan dalam input pertanyaan. Berikut adalah tampilan halaman jawaban tidak ditemukan dapat dilihat pada Gambar 6.

Gambar 4. Interface Halaman Jawaban 


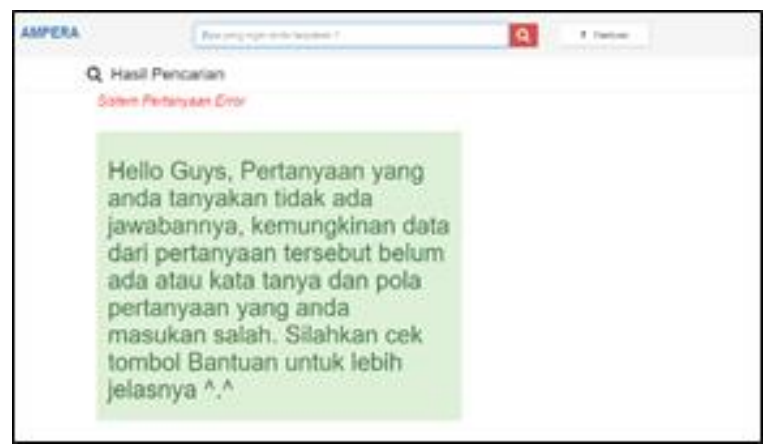

Gambar 6. Interface Halaman Jawaban Tidak Ditemukan

\subsubsection{Interface Halaman Tentang Kami}

Halaman tentang kami digunakan untuk memberikan informasi mengenai profil dari pembuat web Question Answering System informasi pariwisata kota Palembang ini. Berikut adalah tampilan dari halaman interface tentang kami yang dapat dilihat pada Gambar 7

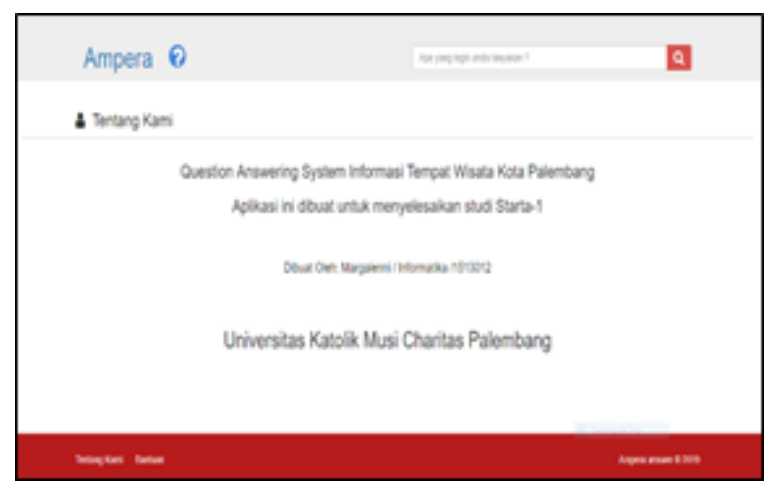

Gambar 7. Interface Halaman Tentang Kami

\subsubsection{Interface Halaman Bantuan}

Halaman bantuan digunakan untuk memberikan informasi mengenai bantuan yang diberikan kepada pengguna atau cara menggunakan web Question Answering System informasi pariwisata kota Palembang. Seperti pertanyaan apa saja yang bisa ditanyakan, kata tanya yang bisa digunakan, dan berbagai macam tipe error yang terdapat pada sistem ini. Berikut adalah tampilan dari halaman Interface bantuan yang dapat dilihat pada Gambar 8.

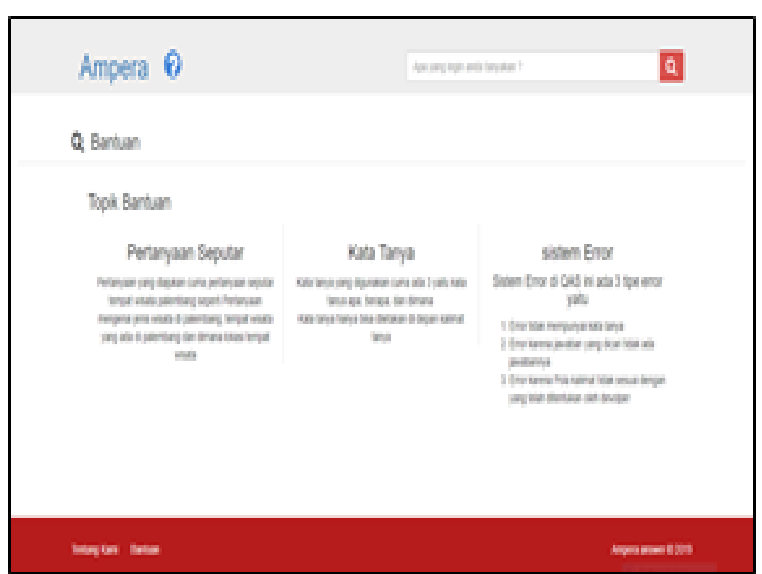

Gambar 8. Interface Halaman Bantuan

\section{HASIL DAN PEMBAHASAN}

\subsection{Pengujian NLP}

NLP (Natural Language Processing) secara teoritis adalah pengembangan berbagai teknik komputasi untuk menganalisis dan menampilkan teks dalam bahasa alami pada suatu atau lebih tingkat analisis linguistik untuk mencapai tujuan manusia dalam hal bahasa yaitu menyelesaikan berbagai tugas atau aplikasi .[10]. Beberapa area utama pada field NLP salah satunya adalah Question Answering System . [11]. Oleh karena itu pada Question Answering System informasi pariwisata kota Palembang ini perlu dilakukan pengujian NLP. Pengujian NLP dilakukan untuk mengetahui berapa persentase sistem dapat memberikan jawaban dengan sesuai berdasarkan pertanyaan yang diajukan oleh pengguna. Sampel pengujian didapat dari beberapa masyarakat yang ada dikota Palembang. Pengguna akan mengajukan pertanyaan-pertanyaan mengenai informasi pariwisata yang ada dikota Palembang. Berikut persentase pertanyaan yang diterima berdasarkan hasil pengujian dapat dilihat pada Tabel 4. 
Tabel 4. Persentase Pertanyaan yang Diterima

\begin{tabular}{lcccc}
\hline $\begin{array}{l}\text { Jenis } \\
\text { Pertanyaan }\end{array}$ & Total & Diterima & Ditolak & $\begin{array}{c}\text { Persentase } \\
\text { Diterima }\end{array}$ \\
\hline $\begin{array}{l}\text { Jenis Tempat } \\
\text { Wisata }\end{array}$ & 17 & 12 & 5 & $70,58 \%$ \\
$\begin{array}{l}\text { Total Tempat } \\
\text { Wisata }\end{array}$ & 24 & 18 & 6 & $75 \%$ \\
$\begin{array}{l}\text { Lokasi Tempat } \\
\text { Wisata }\end{array}$ & 115 & 98 & 17 & $85,21 \%$ \\
\multicolumn{1}{c}{ Total } & $\mathbf{1 5 6}$ & $\mathbf{1 2 8}$ & $\mathbf{2 8}$ & $\mathbf{8 2 , 0 5 \%}$ \\
\hline
\end{tabular}

Berdasarkan dari tabel persentase hasil pengujian yang telah dilakukan terhadap beberapa masyarakat dikota Palembang telah didapatkan 156 pertanyaan yang diajukan oleh pengguna, dimana Question Answering System informasi pariwisata kota Palembang didapatkan 28 pertanyaan yang tidak dapat dijawab dengan sesuai dikarenakan pertanyaan-pertanyaan tersebut tidak mengandung kata tanya, pertanyaan yang ditanyakan jawabannya tidak terdapat di database, serta pola pertanyaan yang ditanyakan tidak terdapat di whitepos. Berdasarkan keseluruhan dari total pertanyaan yang telah diujikan, Question Answering System informasi pariwisata kota Palembang memiliki tingkat keberhasilan atau dapat memberikan jawaban dengan sesuai sebesar $82,05 \%$.

\subsection{Pengujian End User}

Pengujian end users dilakukan untuk menguji aplikasi yang akan dipakai oleh end users apakah aplikasi tesebut sudah sesuai atau belum sesuai. Pengujian end users dilakukan dengan cara menyebarkan kuisioner kepada pengguna aplikasi, dimana pengguna akan mencoba Question Answering System informasi pariwisata kota Palembang secara langsung yang diberi nama Ampera Answer, kemudian setelah pengguna selesai mencoba aplikasi tersebut, pengguna akan diminta untuk memberikan pendapat mereka mengenai aplikasi tersebut dengan cara menuangkannya kedalam kusioner yang telah dibagikan. Sampel pengujian diambil dari beberapa masyarakat dikota Palembang sebanyak 30 responden. Pengujian sampel menggunakan teknik probability sampling dengan metode simple random sampling, yaitu pengambilan secara acak dikarenakan setiap anggota populasi memiliki perluang yang sama untuk terpilih sebagai sampel penelitian. Kuisioner ini menggunakan skala Guttman yang dimana responden hanya dapat menjawab 2 pilihan yaitu setuju atau tidak setuju. Berikut persentase dari hasil pengujian end users yang dapat dilihat pada Tabel 5.

Tabel 5. Persentase Pertanyaan yang Diterima

\begin{tabular}{llcc}
\hline No & \multicolumn{1}{c}{ Pertanyaan } & Diterima & Ditolak \\
\hline 1 & $\begin{array}{l}\text { Apakah Interface Ampera } \\
\text { Answer User Friendly }\end{array}$ & $86,66 \%$ & $13,33 \%$ \\
2 & $\begin{array}{l}\text { Apakah anda mengerti cara } \\
\text { menggunakan aplikasi }\end{array}$ & $83,33 \%$ & $16,67 \%$ \\
& Ampera Answer & \\
3 & $\begin{array}{l}\text { Apakah bantuan yang ada } \\
\text { di aplikasi Ampera Answer } \\
\text { dapat membantu pengguna } \\
\text { untuk menggunakan } \\
\text { aplikasi Ampera Answer }\end{array}$ & $20 \%$ \\
4. & & \\
Pengguna mendapatkan \\
jawaban
\end{tabular}

Dari hasil pengujian yang telah dilakukan terhadap 30 responden terdapat 26 dari 30 responden atau 86,66 \% mengatakan bahwa aplikasi Ampera Answer memiliki tampilan 
interface yang user friendly atau mudah untuk digunakan, sedangkan 4 responden atau 13,33\% mengatakan bahwa tampilan interface aplikasi Ampera Answer tidak user friendly atau tidak mudah digunakan dikarenakan pengguna harus menggunakan kata tanya.

Dari 30 responden hanya 25 responden atau $83.33 \%$ mengatakan bahwa mereka mengerti cara menggunakan aplikasi Ampera Answer, sedangkan 5 responden atau 16,67\% mengatakan bahwa mereka tidak terlalu mengerti cara menggunakan aplikasi Ampera Answer dikarenakan pengguna belum pernah dan belum terbiasa untuk searching menggunakan teknologi.

Bantuan yang membantu penguna untuk menggunakan aplikasi Ampera Answer disetujui oleh 24 responden atau 80\%, sedangkan 6 responden atau $20 \%$ mengatakan bahwa bantuan yang diberikan tidak membantu pengguna dalam menggunakan aplikasi Ampera Answer dikarenakan pengguna merasa sudah mengerti cara menggunakan sistem tersebut tanpa melihat bantuan.

Kemudian yang mendapatkan jawaban yang sesuai dengan pertanyaan yang diberikan oleh pengguna ada 23 dari 30 atau 76,67\% responden yang mengatakan setuju, sedangkan 7 responden atau $23,33 \%$ yang lainnya mengatakan tidak setuju dikarenakan pengguna tidak suka mendapatkan pesan error saat melakukan penggujian.

\section{KESIMPULAN}

Berdasarkan proses dan hasil penelitian Question Answering System informasi pariwisata kota Palembang yang telah dilakukan, maka dapat ditarik beberapa kesimpulan sebagai berikut:

1. Question Answering System informasi pariwisata kota Palembang dapat memahami maksud pertanyaan yang ditanyakan oleh pengguna melalui teknik Preprocessing yaitu Tokenization, POS tagging, dan NER, serta dapat mencocokan metadata pertanyaan dengan metadata yang telah disiapkan.

2. Question Answering System informasi pariwisata kota Palembang dapat memberikan jawaban yang sesuai melalui proses Answer Processing dan merangkai jawaban yang akan ditampilan senatural mungkin.

\section{DAFTAR PUSTAKA}

[1] Bendi, R.K.J., "System Qestion Answering Berbasis Ontologi Sebagai Aplikasi Web Sematik" 2010. Seminar dan Call for Paper Munas Aptikom Politeknik Telkom. Bandung.

[2] Palembang, P.K. "Portal Resmi Pemerintahan Kota Palembang". 2016. [Online]. Available: www.palembang.go.id, [Accessed: 10 Oktober 2018].

[3] Efrizal, R., "Kunjungan Wisatawan ke Kota Palembang Terus Mengalami Peningkatan" 2018. (Online). Available: www.palembang.tribunnews.com, [Accessed: 10 Oktober 2018].

[4] Liu, B.. Data Mining (Edisi ke-2). Springer: Berlin. 2011.

[5] Turban, McLean, \& Wetherbe. Pengenalan Sistem Informasi. Jogjakarta: Andi. 1999.

[6] Bird, S., Loper, E. \& Klien, E.. Natural Language Processing with Python. California: O’Reilly Media. 2009. 
[7] Setiawan, R.A. \& Bendi, R.K.J. "Chitcatcinema: Aplikasi Question Answering System Untuk Domain Film Bioskop." Jurnal Hoaq: Teknologi Informasi, No. 1, Vol. 1, hlm. 211-218. 2014.

[8] Pisceldo, F., Andriani, M. \& Manurung, R. Probabilistic Part Of Speech Tagging for Bahasa Indonesia. Depok: Universitas Indonesia. 2009.

[9] Gunawan \& Lovina, G.. "Question Answering System dan Penerapannya Pada Alkitab”, Jurnal Informatika, No. 1, Vol. 7, hlm 1-9. 2006

[10] Liddy, E.D. Natural Language Processing: In Encyclopedia of Library and Information Science (Edisi ke-2). USA: Marcel Decker Inc. 2001.

[11] Pustejovsky, J. \& Stubbs, A. Natural Language Annotation for Machine Learning. Beijing: O’Reilly. 2012. 